\title{
Development of Rapid Propagation Methods and a Miniature Plant for Export-oriented Foliage, Zamioculcas zamiifolia
}

\author{
K.A.C.N. Seneviratne ${ }^{1 *}$, W.A.M. Daundasekera ${ }^{2}$, S.A. Kulasooriya ${ }^{3}$ and D.S.A. Wijesundara ${ }^{1}$ \\ ${ }^{1}$ Department of National Botanic Gardens, Peradeniya, Sri Lanka \\ ${ }^{2}$ Department of Botany, University of Peradeniya, Peradeniya, Sri Lanka \\ ${ }^{3}$ Institute of Fundamental Studies, Hantana Road, Kandy, Sri Lanka \\ Received: 25 September 2012 / Accepted 30 May 2013
}

\begin{abstract}
Zamioculcas zamiifolia is an ornamental potted foliage plant and a relatively new introduction to the world of interior plants. However, its low growth rate in conventional solid media is a constraint in mass propagation. The present study aimed at developing improved culture techniques that would enhance the growth and rapid propagation of the plant. Three experiments were conducted to find out the best type of vegetative cuttings, the effect of light on plant growth in a liquid (distilled water) medium, and to develop a new solid medium with nutrients to increase the growth rate. Basal leaflets without rachis were found to be the best cutting type for rapid propagation. Solid substrate was better than liquid medium for rapid rooting. Compost + sand $+0.75 \mathrm{~g} \mathrm{l}^{-1}$ fertilizer nutrients can be recommended for rapid propagation of the plant. Plant growth was high in the light-exposed liquid medium compared to dark treatment. Interestingly, the liquid medium led to development of a miniature plant which could be introduced as a novel table-top ornament. The results of the present study would contribute immensely to the export industry of Z. zamiifolia.
\end{abstract}

Key words: culture techniques, cuttings, liquid medium, ornamental plants, solid medium

\section{INTRODUCTION}

Zamioculcas zamiifolia (Lodd.) Engl. (Commonly called Zz plant) (Figure 1a) is a tropical perennial, evergreen plant native to South Africa (Lopez et al., 2009). It is a stem-less herbaceous, monocotyledonous plant in the family Araceae (Feng et al., 2006; Wong, 2009). Z. zamiifolia was discovered in 1905 (Mayo et al., 1998 ) and it is the only species belonging to the genus Zamioculcas (Chen et al., 2004; Wong, 2009). The botanical name is derived from the superficial similarity of its foliage to that of the cycad genus Zamia (Reid and Cevallos, 2009).

Growers in Florida were the first to venture into mass scale production of Z. zamiifolia as an ornamental in the year 1999 (Harrison, 2009) and since then, it has emerged as an important foliage plant for interiorscaping and a festive decorative plant (Wong, 2009; Brown, 2000; Chen et al., 2002; Chen et al., 2004; Papafotiou and Martini, 2009). Within three years from its first introduction, this plant has become so popular that it was named as the 'plant of the year' in 2002 by the Florida Nurserymens' and Growers Association (Harrison, 2009).

The species is found to be naturally occurring in both dry grasslands as well as lowland forests, on rocky, lightly shaded terrain, but infrequently under deep shade (Mayo et al., 1998). It grows outdoors as long as the temperature does not fall below $15^{\circ} \mathrm{C}$, but the best growth is between $18^{\circ} \mathrm{C}$ and $26^{\circ} \mathrm{C}$ and with the relative humidity between 50\% and 95\% (Chen et al., 2004; Reid and Cevallos, 2009).

Z. zamiifolia is different from most other foliage plants being a stem-less, herbaceous forest plant that develops short sprouts from a thick underground tuber-like rhizome that stores water (Wong, 2009). Due to this rhizome, the plant can survive without water for longer periods. Though the rhizome is an attractive feature, it is unobserved due to its underground growth. The waxy and shiny leaves with extremely low rates of transpiration and fleshy stems also contribute to its drought tolerant ability. All the parts of the plant are poisonous if ingested by domestic animals as they contain rhaphides and/or druses of calcium oxalate (Wong, 2009).

Z. zamiifolia is propagated through leaf cuttings (Lopez et al., 2009) and a well-drained, friable mixture is usually the preferred substrate (Wong, 2009). It is conventionally grown in a peat-based solid medium. However, low growth rate in the medium is a constraint in mass propagation.

*Corresponding author's email: champasenevirathne@yahoo.com 
Over-watering may destroy the plant and damp soil will cause the rhizome to rot. The succulent bulb-like structures arising from the leaves may be potted to produce new plants (Reid and Cevallos, 2009). If this plant could also be grown in liquid media, the attractive rhizome can be made visible. In general, the use of liquid culture media for horticultural crops has another important advantage, i.e., they may tend to naturally form root-microbial (e.g. cyanobacteria) associations that could help reduce nutrient requirement, thus requiring only low or moderate levels of fertilizers, which support reduced disease incidences and increased plant growth for rapid propagation (Gosselin and Trudel, 1984; Rai et al., 2002; Chiu et al., 2005; Seneviratne, 2012). Furthermore, light may affect plant root, and hence the overall growth of plant, when grown in liquid media. Hence, the current study was aimed at developing improved culture techniques that would enhance the growth and rapid propagation of $Z$. zamiifolia.

\section{MATERIALS AND METHODS}

\section{Propagation methods}

The first experiment was designed to determine the best type of vegetative cuttings bearing leaflets at different maturity stages that would initiate roots rapidly during propagation in solid medium (Figure 1b). Six types of cuttings were harvested from stock plants growing in a net house with $70 \%$ shade: a basal leaflet without rachis $(6.5 \mathrm{~cm})$ [Figure 1 (b) - 1], two basal leaflets with rachis [Figure 1 (b) - 2], a middle leaflet without rachis [Figure 1 (b) -3 ], two middle leaflets with rachis [Figure 1 (b) -4 ], a terminal leaflet without rachis [Figure $1(\mathrm{~b})-5$ ], and two terminal leaflets with rachis [Figure 1 (b) $-6]$.

All different types of cuttings were propagated in solid medium [(plastic pots of $11 \mathrm{~cm}$ diameter, filled with $50 \%$ leaf litter compost and $50 \%$ coarse sand mix, applied with distilled water $(\mathrm{pH}$ 5.7 and EC $\left.9.6 \mu \mathrm{S} \mathrm{cm}^{-1}\right)$ ]. The pots were kept in moist chambers inside the laboratory for rooting. Based on our preliminary observations, nutrients were not added to the media, as they reduce callus formation which is important for root initiation. Air temperature of the propagation environment was $28^{\circ} \mathrm{C}$ with a 16 -hour photoperiod (Lopez et al., 2009) under illumination from two cool-white florescent lights of ca. $3 \mu \mathrm{mol} \mathrm{m} \mathrm{m}^{-2} \mathrm{~s}^{-1}$ light intensity at foliage level. Four weeks after propagation, observations were made on callus and root initiation.
Thereafter, two experiments were conducted to examine the effect of liquid media on rooting of $Z$. zamiifolia and to develop a liquid nutrient medium to increase the plant growth. Further, the liquid nutrient medium was coupled with the solid medium to test whether the plant growth could be further improved. As the first stage of this experiment, the best rooted cutting type selected from the first experiment was propagated in distilled water as the simplest liquid medium. Subsequently, it was compared with the solid medium as a reference, in order to investigate the effect of the medium on rooting properties. As the second stage, the best cutting type was again propagated and transferred into liquid nutrient media containing fertilizer at different concentrations $\left(0.37,0.75\right.$, and $1.5 \mathrm{~g} \mathrm{l}^{-1}$ of $\mathrm{N}: \mathrm{P}: \mathrm{K}$ $6: 30: 30$ with micronutrients $[0.05 \% \mathrm{Zn}, 0.05 \%$ $\mathrm{Cu}, 0.02 \% \mathrm{~B}, 0.0005 \% \mathrm{Mo}, 0.05 \% \mathrm{Mg}, 0.1 \%$ $\mathrm{Fe}])$. Distilled water was used as the control. Initial root number, root length and initial plant fresh weight were measured. The plants were grown at $28{ }^{\circ} \mathrm{C}$ under a 16 -hour photoperiod for 6 weeks. Then, final root number, root length, sprout length, leaf chlorophyll content (chlorophyll meter SPAD-502, China, Tiancheng et al., 2000), and plant fresh weight were measured to select the best concentration of fertilizer. Increases in root number, root length and plant fresh weight were expressed as a fraction to the initial values. Ten replicates were maintained for these experiments.

Subsequently, the experiment was extended to evaluate the effects of the liquid and solid media on rooting and growth. For this, the best cutting type was transplanted into different media containing the best concentration of fertilizer, i.e., liquid medium (M1); sand + M1 (M2); leaf litter compost + sand, 1:1 (M3); and M3 + M1 (M4). The initial root and rhizome dry weight and initial plant dry weight were measured using ten random plants. The treated cuttings of the third stage were kept in the laboratory and were maintained at 28 ${ }^{\circ} \mathrm{C}$ under a 16 hour photoperiod with cool-white fluorescent light. After 6 weeks, plant height, increase in root number and length, sprout (new shoot) length, leaf chlorophyll content, disease incidences (visual observation) and plant fresh and oven dry weights $\left(65^{\circ} \mathrm{C}\right.$ to constant weight; ten replicates) were recorded. The increase in root + rhizome dry weight and the increase in total plant dry weight were expressed as a fraction by dividing the increase of each parameter by its initial value. Visual observations of the other ten replicates were continued for up to 14 weeks, but they were not harvested and measured. 
The third experiment was conducted to evaluate the effect of light on plant growth in liquid medium (distilled water). Nutrients were not added, as it is well known that chemical $\mathrm{N}$ fertilizers suppress $\mathrm{N}_{2}$ fixers that supply $\mathrm{N}$ to the microbial community. This tends to suppress biological control agents in the community due to reduced $\mathrm{N}$ supply with retarded biological nitrogen fixation. Hence, nutrient addition increases disease incidence (Seneviratne, 2012). The best rooted cuttings were transferred to twenty glass tubes filled with one-third of distilled water and plugged with cotton wool. The root zone of half (10) of the tubes were covered with aluminum foil to exclude light from the root zone. The remaining tubes were kept without the aluminum foil wrapping. The growing conditions of the propagation environment were $28{ }^{\circ} \mathrm{C}$ with a 16-hour photoperiod. Four weeks after the treatment, observations were made on the root number, root length and fresh weight of the rooted plants. The increase in root length and root number was expressed as a fraction of the initial value of each parameter and the increase in fresh weight was expressed as a percentage to the initial value.

All these experiments were conducted at the Royal Botanic Garden, Peradeniya.

\section{Experimental design and data analysis}

All three experiments were arranged in completely randomized designs. Data with percentage values were analyzed using the $\chi^{2}$ test. Other data were analyzed using ANOVA after normality and residual tests, and mean separation was carried out using Tukey's HSD test at P < 0.05. All data were analyzed using the SAS statistical software (SAS, 1998).

\section{RESULTS AND DISCUSSION}

\section{Best vegetative cutting type}

Among the vegetative cutting types tested, the basal, middle and terminal leaflets without rachis (1, 3 and 5 cutting types, respectively) showed apparently better callus formation in solid medium, compared to the leaflet pairs with rachis (Figure 2). However, only the basal leaflet without rachis showed a significantly higher $(\mathrm{P}<$ $0.05)$ callus formation than that of the cutting types with rachis. Root number (Figure 3a) was significantly higher $(\mathrm{P}<0.05)$ in the basal leaflet without rachis, middle leaflet without rachis and two terminal leaflets with rachis than in the other cutting types. Root length was significantly higher in the basal leaflet without rachis than the two basal leaflets with rachis, terminal leaflet without rachis and two terminal leaflets with rachis $(\mathrm{P}<0.05)$.

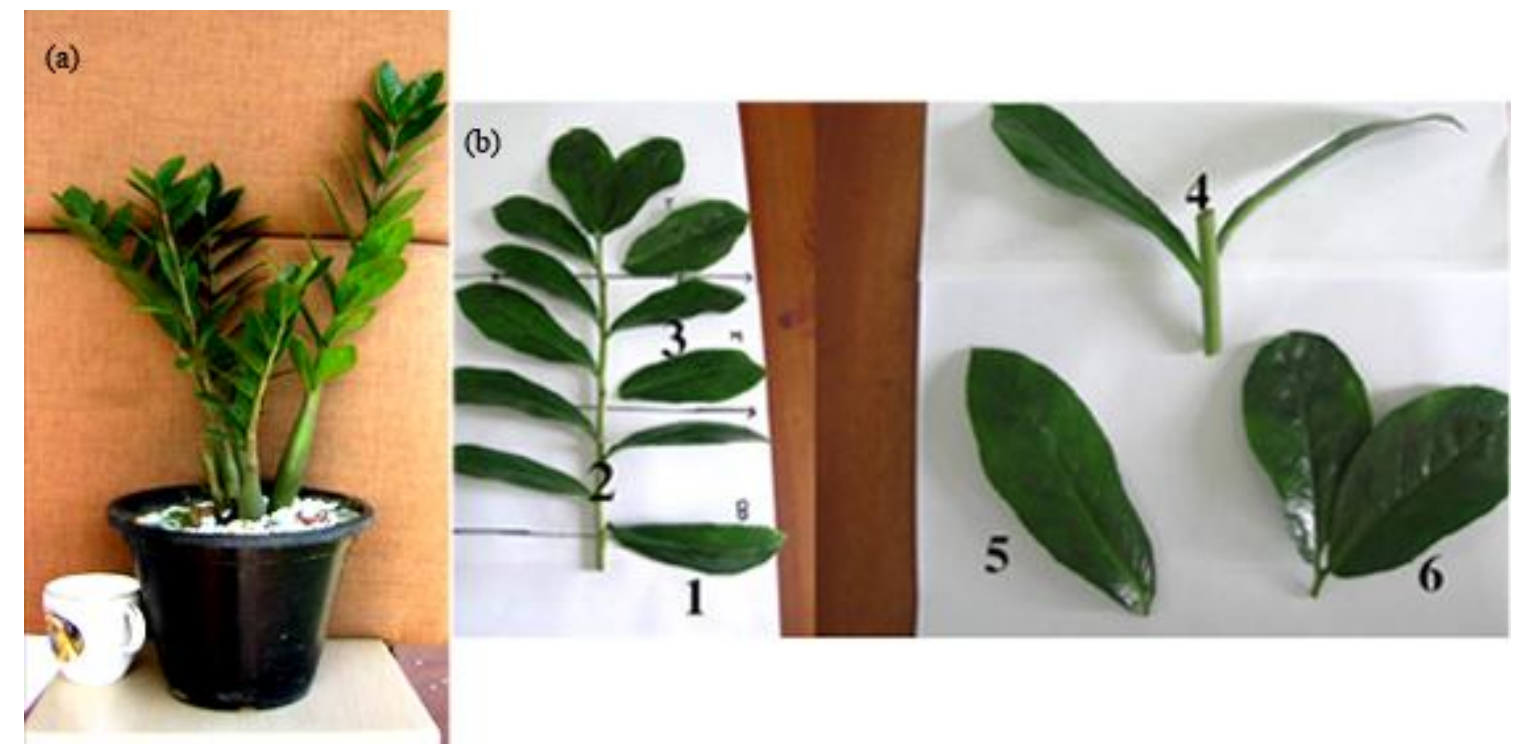

Figure 1 (a). Habit of Z. zamiifolia. (b) Different maturity stages and cutting types of Z. zamiifolia selected for rapid propagation. Treatment numbers: 1 - Basal leaflet without rachis, 2 - two basal leaflets with rachis, 3 - middle leaflet without rachis, 4 - two middle leaflets with rachis, 5 - terminal leaflet without rachis, 6 two terminal leaflets with rachis. 


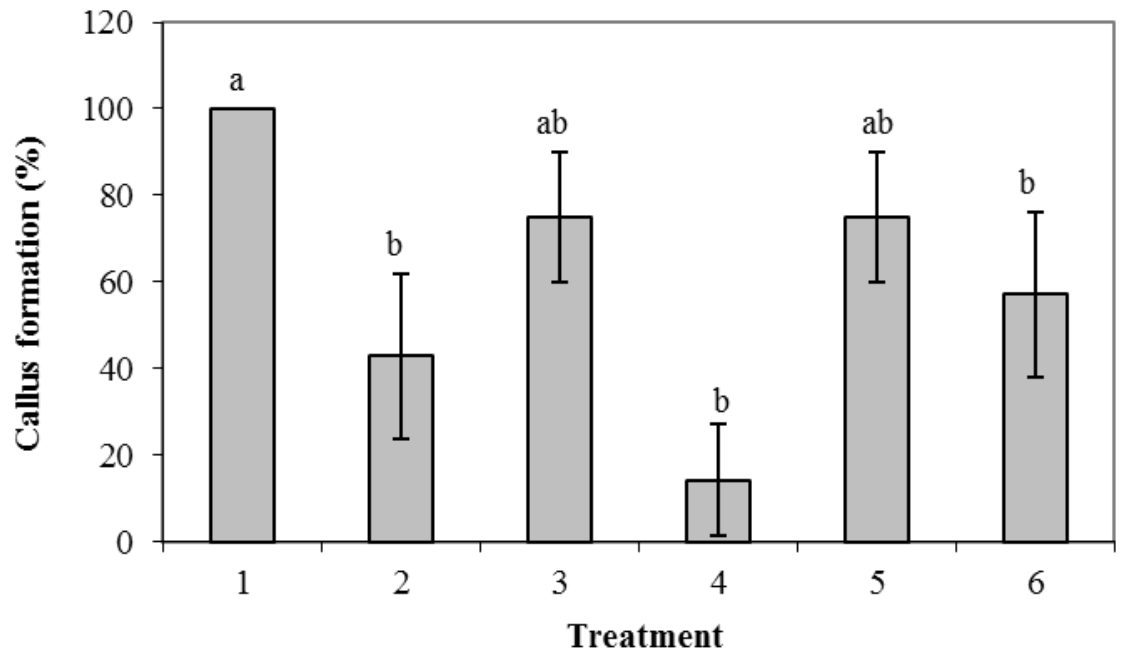

Figure 2. Effect of the type of planting material on callus formation by Z. zamiifolia in solid medium. Treatment numbers are as given in Figure 1 (b). Treatment columns headed by the same letter are not significantly different at $5 \%$ probability level, according to $\chi^{2}$ test. Vertical bars show standard errors.

Table 1. Effect of growing media on rooting properties of Z. zamiifolia

\begin{tabular}{lcc} 
Treatment & Final root number per plant & Final root length $\left(\mathrm{cm} \mathrm{plant}^{-1}\right)$ \\
\hline Solid medium (compost:sand, 1:1) & $3.75^{\mathrm{a}} \pm 0.63$ & $6.88^{\mathrm{a}} \pm 1.14$ \\
Liquid medium (distilled water) & $4.35^{\mathrm{a}} \pm 0.28$ & $4.13^{\mathrm{b}} \pm 0.17$
\end{tabular}

Mean \pm SE. Values in the same column followed by the same letter are not significantly different at $5 \%$ probability level, according to $t$ test.

Root length of the middle leaflet without rachis was not significantly different $(\mathrm{P}>0.05)$ from that of the two terminal leaflets with rachis, (Figure $3 b)$. Thus, the basal leaflet without rachis was selected as the best cutting type and maturity stage for rapid propagation, in terms of rooting. Lopez et al. (2009) reported that under relatively low light intensity, rapid propagation of $Z$. zamiifolia can also be achieved by apical leaflet cuttings.

\section{Suitable growing medium}

The results of the first experiment suggest that $Z$. zamiifolia can be rooted in liquid media (Table 1), although the solid medium was better than the liquid medium for root elongation. Root number was not significantly different between the two media. During the first 6 weeks, fresh weight increase and sprout length of rooted cuttings decreased as the concentration of fertilizer was increased (Table 2). This could be attributed to high concentrations of fertilizers which could be toxic to the plant, or to the detrimental effects of fertilizers on the beneficial plant root-microbial associations. For example, Siddiqi et al. (2002) observed that the accumulation of ammonium in the liquid medium caused a toxicity that reduced plant growth.

Properties of rooting peaked at a concentration of $0.75 \mathrm{~g} \mathrm{l}^{-1}$ fertilizer, but the treatments were not significantly different $(\mathrm{P}>0.05$, Table 2). Chlorophyll content was also the highest in the same treatment and it was not significantly different only from $1.5 \mathrm{~g} \mathrm{l}^{-1}$ fertilizer. Initial sprouting was low at $0.75 \mathrm{~g} \mathrm{l}^{-1}$ fertilizer, which was also reflected from the increase in plant fresh weight. Necrosis of leaves due to diseases was 
lower in distilled water $(33 \%)$ and $0.75 \mathrm{~g} \mathrm{l}^{-1}$ fertilizer (36\%) than in $1.5 \mathrm{~g} \mathrm{l}^{-1}$ fertilizer (55\%). As such, the treatment with $0.75 \mathrm{~g} \mathrm{l}^{-1}$ fertilizer was selected as the best nutrient medium for further testing, based on low disease incidence and high chlorophyll content. Even after 14 weeks, visual growth was better in the same treatment than other treatments indicating its suitability.

After transplanting in different growing media, it was found that the M4 treatment (i.e. compost + sand + M1) produced significantly higher increase in plant dry weight compared to the other treatments (Table 3). Root + rhizome dry weight and chlorophyll content in sprouts were also higher in M4, though not significantly different from the other treatments $(\mathrm{P}>0.05)$. Treatment M1 showed sprout initiation only after 13-14 weeks. Thus, M4 (compost + sand $+0.75 \mathrm{~g} \mathrm{l}^{-1}$ fertilizers) medium can be recommended for rapid propagation of $Z$. zamiifolia. There is no literature available on improved culture media for rapid propagation of $Z$. zamiifolia.

(a)

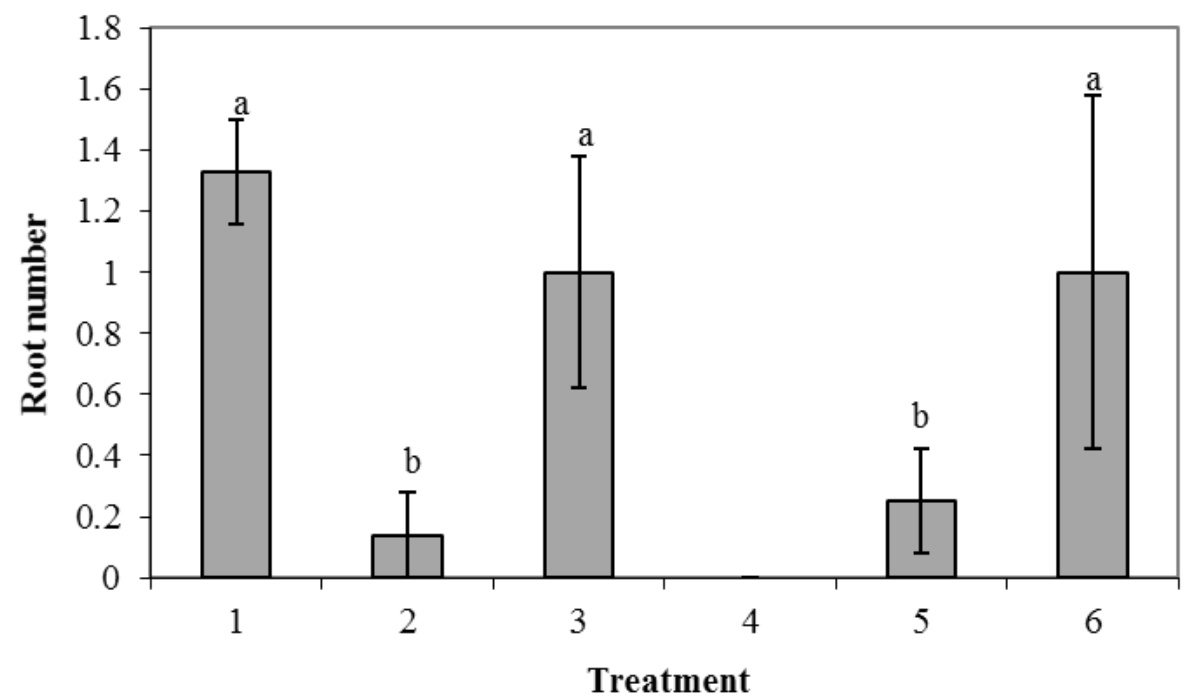

(b)

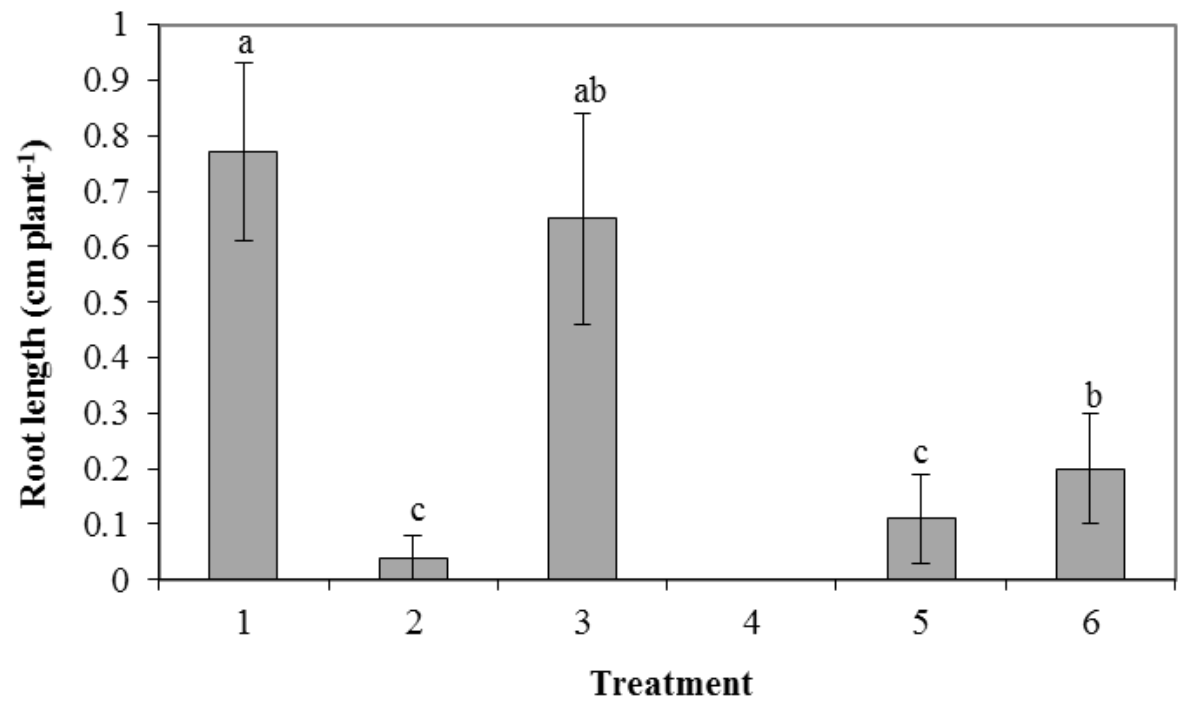

Figure 3. Effect of the type of planting material on (a) root number, and (b) root length of Z. zamiifolia in the solid medium. Treatment numbers are as for Figure 2. Treatment columns with the same letter are not significantly different at 5\% probability level, according to Tukey’s HSD test. Vertical bars denote standard errors 


\section{Effect of light on root zone}

Root length and fresh weight increases were significantly higher in light-exposed treatment compared to dark treatment (Fig. 4). This could be attributed to the growth of algae and $\mathrm{N}_{2}$ fixers on the light-exposed root system (Figure 5a). Plant growth improvements due to root- $\mathrm{N}_{2}$ fixing cyanobacterial associations in liquid media have been reported in wheat, corn, bean, sugar beet and rice (Svircev et al., 1997). Another possibility is the development of chloroplasts in the lightexposed roots. This needs further investigation to confirm whether it is due to cyanobacterial associations or chloroplast development, or both.

\begin{abstract}
A novel table-top miniature plant
Initial sprouting and fresh weight increase were relatively high in the distilled water, though not significant $(\mathrm{P}>0.05$, Table 2$)$. It has been reported that over-watering might destroy this plant and damp soil would cause the rhizome to rot in solid media (Wong, 2009). However, such negative effects were not observed in the liquid media. When the root system was exposed to light in distilled water, root length and plant growth were increased significantly $(\mathrm{P}<0.05$, Figure 4), possibly due to reasons mentioned above. The liquid medium made the rhizome and the root system visible (Figure 5b).
\end{abstract}

Table 2. Effect of fertilizer concentration on growth of Z. zamiifolia in liquid medium after 6 weeks

\begin{tabular}{llllll}
\hline Treatment & $\begin{array}{l}\text { Plant fresh } \\
\text { weight increase } \\
\left(\mathrm{g} \mathrm{g}^{-1}\right) \#\end{array}$ & $\begin{array}{l}\text { Root } \\
\text { number } \\
\text { increase } \\
\text { per plant }\end{array}$ & $\begin{array}{l}\text { Root length } \\
\text { increase } \\
\left(\mathrm{cm} \mathrm{cm}^{-1}\right) \#\end{array}$ & $\begin{array}{l}\text { Sprout length } \\
\left(\mathrm{cm} \mathrm{plant}^{-1}\right)\end{array}$ & $\begin{array}{l}\text { Chlorophyll } \\
\text { content of } \\
\text { rooted cuttings } \\
(\mathrm{SPAD})\end{array}$ \\
\hline Distilled water & $0.309^{\mathrm{a}}$ & $0.914^{\mathrm{a}}$ & $1.988^{\mathrm{a}}$ & $4.02^{\mathrm{a}}$ & $43.8^{\mathrm{b}}$ \\
$0.37 \mathrm{~g} \mathrm{l}^{-1}$ & $0.238^{\mathrm{ab}}$ & $1.115^{\mathrm{a}}$ & $1.577^{\mathrm{a}}$ & $4.44^{\mathrm{a}}$ & $45.4^{\mathrm{b}}$ \\
$0.75 \mathrm{~g} \mathrm{l}^{-1}$ & $0.165^{\mathrm{ab}}$ & $1.322^{\mathrm{a}}$ & $2.03^{\mathrm{a}}$ & $1.70^{\mathrm{bc}}$ & $57.7^{\mathrm{a}}$ \\
$1.5 \mathrm{~g} \mathrm{l}^{-1}$ & $0.092^{\mathrm{b}}$ & $1.264^{\mathrm{a}}$ & $1.12^{\mathrm{a}}$ & $0.80^{\mathrm{c}}$ & $53.6^{\mathrm{ab}}$ \\
$\mathrm{MSD}(0.05)$ & 0.155 & 0.885 & 1.383 & 2.55 & 12.1 \\
$\mathrm{CV}(\%)$ & 41.0 & 40.9 & 3.8 & 49.6 & 12.9 \\
\hline
\end{tabular}

Values in the same column followed by the same letter are not significantly different at 5\% probability level, according to Tukey's HSD test. \#Given as a fraction to the initial value. MSD - Minimum Significant Difference. CV - Coefficient of Variation.

Table 3. Effect of growing media on chlorophyll content of sprouts and plant growth of Z. zamiifolia after 6 weeks

\begin{tabular}{lccc}
\hline Growing medium & $\begin{array}{c}\text { Sprout chlorophyll } \\
\text { content (SPAD) }\end{array}$ & $\begin{array}{c}\text { Total plant dry weight } \\
\text { increase }\left(\mathrm{g} \mathrm{g}^{-1}\right) \#\end{array}$ & $\begin{array}{c}\text { Root + rhizome dry } \\
\text { weight increase }\left(\mathrm{g} \mathrm{g}^{-1}\right) \#\end{array}$ \\
\hline M1 $\left(0.75 \mathrm{~g} \mathrm{l}^{-1}\right.$ fertilizers) & ND & $0.54^{\mathrm{b}}$ & $0.134^{\mathrm{a}}$ \\
M2 $\left(0.75 \mathrm{~g} \mathrm{l}^{-1}\right.$ fertilizers + sand) & $27.0^{\mathrm{a}}$ & $0.81^{\mathrm{b}}$ & $0.139^{\mathrm{a}}$ \\
M3(compost + sand) & $30.1^{\mathrm{a}}$ & $1.31^{\mathrm{b}}$ & $0.210^{\mathrm{a}}$ \\
$\begin{array}{l}\text { M4 (compost + sand } \\
+0.75 \mathrm{~g} \mathrm{l^{-1 }} \text { fertilizers) }\end{array}$ & $30.8^{\mathrm{a}}$ & $2.30^{\mathrm{a}}$ & 4.42 \\
MSD $(0.05)$ & 4.17 & 4.42 & 31.1 \\
CV $(\%)$ & 18.0 & 35.8 & \\
\hline
\end{tabular}

Values in the same column followed by the same letter are not significantly different at 5\% probability level. ND - Not Detected, due to no sprout formation. \#Given as a fraction to the initial value. MSD Minimum Significant Difference. CV - Coefficient of Variation. 


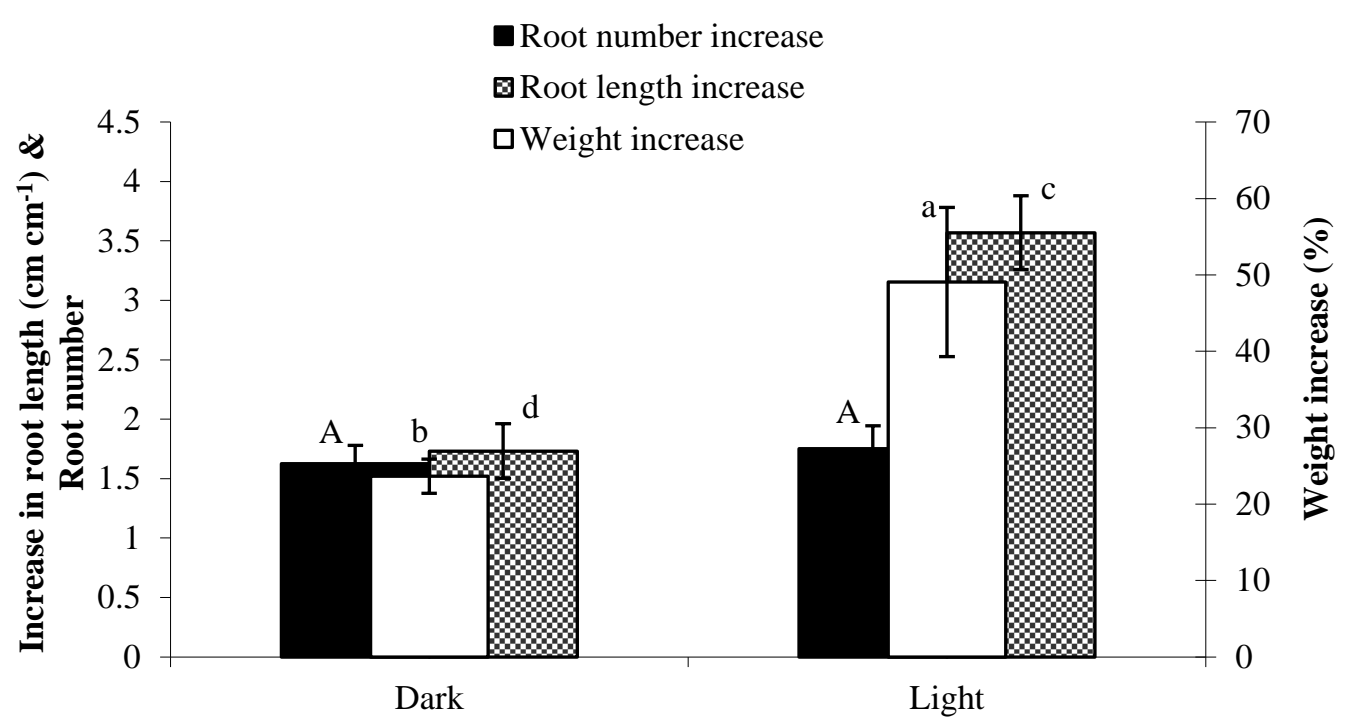

Figure 4. Effect of light on the root zone and growth of Z. zamiifolia during 4 weeks (Different letters indicate significant differences between dark and light treatments).
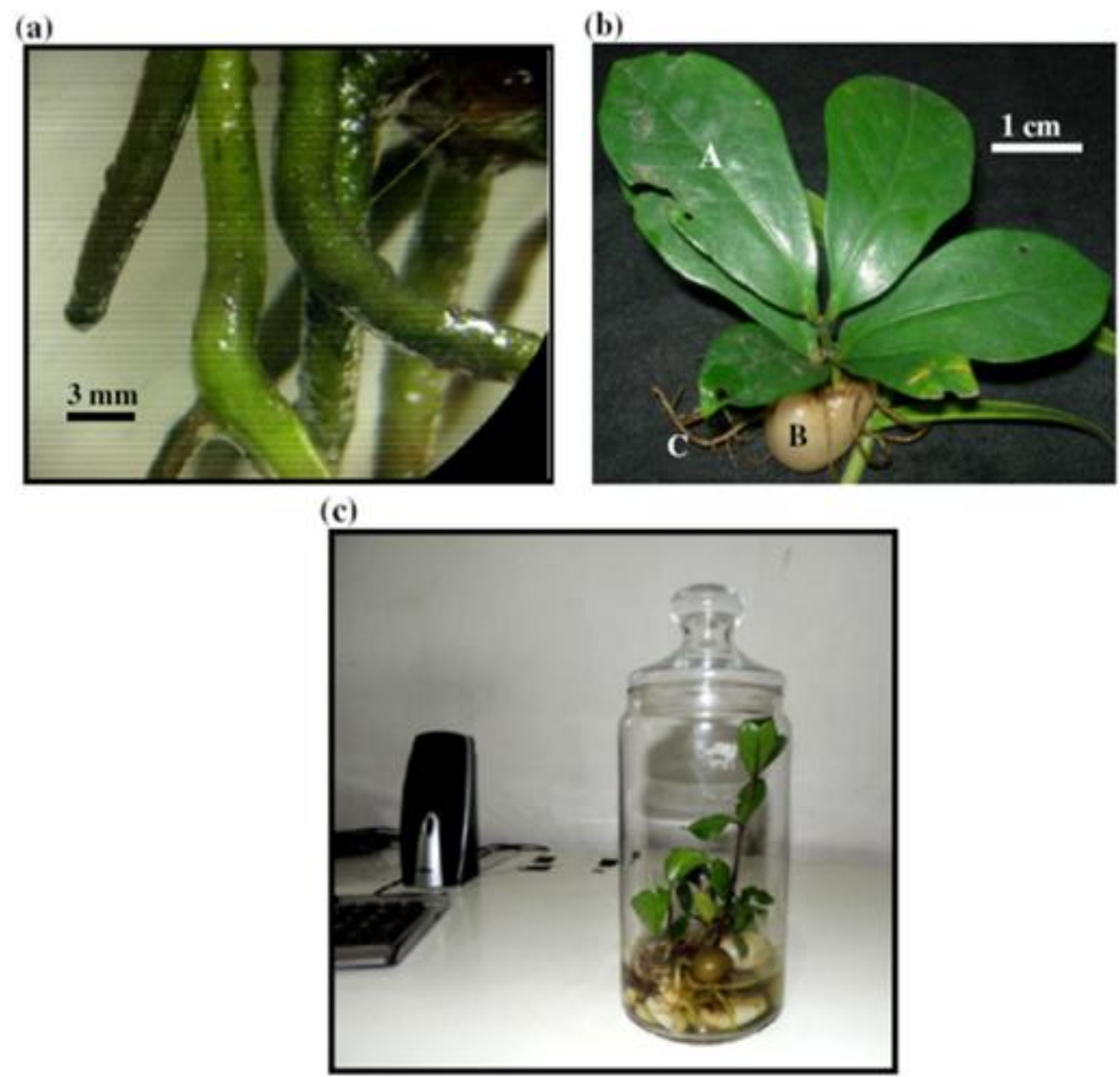

Figure 5. (a) Growth of algae and/or chloroplast development in the light-exposed root system in liquid media, (b) plant with a frond, the rhizome and roots, and (c) novel table-top miniature plant of Z. zamiifolia. 
However, plant growth was constrained due to lack of nutrients in distilled water. This may have led to the development of miniature $Z$. zamiifolia plants, which could be introduced as a novel table-top plant (Figure 5c).

In conclusion, growth rate of $Z$. zamiifolia can be increased for rapid propagation, when basal leaflets without a rachis are grown in compost + sand medium with $0.75 \mathrm{~g} \mathrm{l}^{-1}$ of fertilizer in liquid medium. However, the plant will need to be repotted in a medium like coir dust for exporting. Miniature ornamental plants can be developed in distilled water with light. The results of the present study would contribute immensely to the export industry of $Z$. zamiifolia.

\section{ACKNOWLEDGEMENTS}

The authors would like to thank the Department of National Botanic Gardens, Peradeniya, Sri Lanka for providing financial assistance and facilities required for carrying out this investigation. The assistance given by Dr. S.A. Krishnarajah (Deputy Director, Research and Development) and Mr. K.N. Yapa (Director, Research and Development) of Department of National Botanic Gardens is also acknowledged.

\section{REFERENCES}

Brown, D. (2000). Aroids: Plants of the Arum family. $2^{\text {nd }}$ Edition. Timber Press, Portland, Oregon.

Chen, J., Henny, R.J. and McConnell, D.B. (2002). Development of new foliage plant cultivars. In: J.J. Janik and A. Whipkey (Eds), Trends in New Crops and New Uses, ASHS Press, Alexandria, Pp. 466-472.

Chen, J., Henny, R.J. and McConnell, D.B. (2004). Cultural Guidelines for Commercial Production of Interiorscape ZZ (Zamioculcas zamiifolia). Available from http://edis.ifas.ufl.edu/ep. Accessed on 14 August 2012.

Chiu, W.L., Peters, G.A., Levieille, G., Still, P., Cousins, S., Osborne, B. and Elhai, J. (2005). Nitrogen deprivation and symbiotic gland development. Plant Physiology 139: 224-230.

Feng, C.T., Ho, W.C. and Chao, Y.C. (2006). Basal petiole rot and plant kill of Zamioculcas zamiifolia caused by Phytophthora nicotianae. Plant Disease 90: 1107-1109.

Gosselin, A. and Trudel, M.J. (1984). Interactions between root-zone temperature and light levels on growth, development and photosynthesis of Lycopersicon esculentum Mill. cultivar 'Vendor'. Scientia Horticulturae 23: 313-321.

Harrison, M. (2009). The Incredible ZZ plant (Zamioculcas zamiifolia). Available from www.davesgarden.com. Accessed on 14 August 2012.

Lopez, R.G., Blanchard, M.G. and Runkle, E.S. (2009). Propagation and production of Zamioculcas zamiifolia. Acta Horticulturae 813: 559-564.

Mayo, S.J., Bogner, J. and Boyce, P.C. (1998). The Genera of Araceae. Royal Botanic Gardens, Kew. Pp. 370.

Papafotiou, M. and Martini, A. (2009). Effect of position and orientation of leaflet explants with respect to plant growth regulators on micropropagation of Zamioculcas zamiifolia Engl. (ZZ). Scientia Horticulturae 120: 115120.

Rai, A.N., Bergman, B. and Rasmussen, U. (2002). Cyanobacterial-plant Symbiosis. Kluwer Academic Publishers, Dordrecht. Pp. 355.

Reid, M.S. and Cevallos, J.C. (2009). Postharvest biology and technology for new floricultural crops. Acta Horticulturae 813: 209-216.

SAS (1998). Guide for personal computers. $6^{\text {th }}$ Edition. SAS Institute Inc., Cary, NC.

Seneviratne, G. (2012) Are we wrong in conventional approach of biocontrol? Current Science 103: 1387-1388.

Siddiqi, M.Y., Malhotra, B., Min, X. and Glass, A.D.M. (2002). Effect of ammonium and inorganic carbon enrichment on growth and yield of a hydroponic tomato crop. Journal of Plant Nutrition and Soil Science 165: 191-197.

Svircev, Z., Tamas, I., Nenin, P. and Drobac, A. (1997). Co-cultivation of $\mathrm{N}_{2}$-fixing cyanobacteria and some agriculturally important plants in liquid and sand cultures. Applied Soil Ecology 6: 301-308.

Tiancheng, A., Fangmin, L., Zhian, Z., Min, Z. and Hairong, W. (2000). Relationship between chlorophyll meter readings (SPAD readings) and chlorophyll content of crop leaves. Journal of Hubei Agricultural College 20: 6-8.

Wong, W. (2009). The Garden Plants of China. Green Culture Singapore. Available from www. gardeningwithwilson.com. 